\title{
Allocution du R.P. Adrien Pouliot, s.j. au dîner de clôture
}

\section{Adrien Pouliot}

Volume 37, 1970

La vie religieuse au Manitoba

URI : https://id.erudit.org/iderudit/1007287ar

DOI : https://doi.org/10.7202/1007287ar

Aller au sommaire du numéro

\section{Éditeur(s)}

Les Éditions Historia Ecclesiæ Catholicæ Canadensis Inc.

\section{ISSN}

0318-6172 (imprimé)

1927-7067 (numérique)

Découvrir la revue

\section{Citer ce document}

Pouliot, A. (1970). Allocution du R.P. Adrien Pouliot, s.j. au dîner de clôture. Sessions d'étude - Société canadienne d'histoire de l'Église catholique, 37, 259-260. https://doi.org/10.7202/1007287ar

Tous droits réservés @ Les Éditions Historia Ecclesiæ Catholicæ Canadensis Inc., 1972
Ce document est protégé par la loi sur le droit d'auteur. L'utilisation des services d'Érudit (y compris la reproduction) est assujettie à sa politique d'utilisation que vous pouvez consulter en ligne.

https://apropos.erudit.org/fr/usagers/politique-dutilisation/ 


\section{Allocution du R.P. Adrien Pouliot, s.j. au dîner de clôture}

Hier, 5 juin, en la fête du Sacré-Cœur, qui coïncidait avec celle de saint Boniface, ensemble, dans la chapelle du collège, nous avons remercié le Seigneur du magnifique succès de ce congrès. Aujourd'hui, c'est le Christ et son Église, pour le service de qui nous œuvrons dans la Société canadienne d'histoire de l'Église catholique, c'est le Christ et c'est l'Église qui, par l'humble intermédiaire de votre président, remercient tous les artisans humains d'un pareil succès.

Il est bon de se rendre compte de l'imposant travail et du généreux dévouement qu'a requis, pendant neuf mois d'affilée, la préparation matérielle, intellectuelle, spirituelle de ce congrès: la structuration d'un programme en fonction à la fois du centenaire du Manitoba et des objectifs propres de notre société; la recherche des meilleurs conférenciers, des présidents et des commentateurs les plus aptes, de l'orateur le plus incisif pour le banquet - toutes gens qui ne sont pas du premier coup disponibles; le choix des collaborateurs locaux, à tous les niveaux et dans tous les domaines: invitations, accueil, publicité, logement, aménagement des salles et d'une cafétéria, organisation du dîner de clôture; et, couvrant le tout, la quête de fonds préalables et la responsabilité d'un budget dont la priorité est l'économie!

A tous ceux, donc, qui, de quelque manière que ce soit, dans l'ombre et le silence ou à la vue de tous, ont contribué au succès de ce congrès, le ciel et la terre disent: MERCI !

Une reconnaissance particulière est due - et nous la présentons avec enthousiasme - au personnel de l'archevêché, des presbytères et des communautés religieuses, pour leur si délicate hospitalité; aux autorités du Collège de Saint-Boniface qui ont mis gratuitement à notre disposition, entre autres locaux, la bibliothèque et ce gymnase; à Leurs Excellences $\mathrm{M}^{\mathrm{gr}}$ Baudoux et $\mathrm{M}^{\mathrm{gr}}$ Hacault, ainsi qu'à tant de prêtres, de religieux, de religieuses et de laïcs de tout âge, qui nous ont fait l'honneur d'assister assidûment à nos conférences et dont la présence, ce soir, nous est si agréable.

C'est l'auditoire qui fait le conférencier. L'auditoire d'ici fut extrêmement sympathique. On me permettra de signaler un fait indéniable, à savoir que la présence quotidienne et active de $\mathrm{M}^{\mathrm{gr}} \mathrm{l}^{\text {'archevêque, }}$ calepin, crayon et documents en mains, fut, grâce aux questions qu'il 
a posées et aux éclaircissements qu'il a fournis, l'un des facteurs les plus pesants de l'excellent rendement de nos diverses séances.

Je m'en voudrais de ne pas unir à cette contribution efficace de $\mathrm{M}^{\mathrm{gr}}$ Baudoux celle de $\mathrm{M}$. le juge Monnin et de l'équipe de ses automobilistes, pour l'intéressante promenade historique de cet après-midi.

Il y a enfin les corps publics. Si le Comité d'organisation, sous la responsabilité compétente et dévouée du professeur Lionel Dorge, a pu, malgré de prudentes inquiétudes, entreprendre grand et réaliser magnifique, à notre entière satisfaction et à la vôtre; si de l'Est, une trentaine de personnes au moins ont pu «monter au Manitoba " pour le congrès, séjourner ici cinq jours pleins et retourner chez elles, en avion, demain; si, ce soir, nous avons pu nous régaler ensemble dans des agapes fraternelles en si fraternelle compagnie, avec ce dessert spirituel de haute qualité que nous a présenté le père Émile Legault, nous le devons à l'intelligente administration des deniers publics, qui nous a valu, de la part du ministère des Affaires culturelles de la province de Québec (Service du Canada français d'outre-frontières), un octroi de trois mille dollars et, de la part du Gouvernement du Manitoba, représenté ici par le député Jean Allard, l'octroi de cinq cents dollars qui, avec votre généreuse contribution, à chacun, nous a nourris, ce soir, de ce pain et de ce beurre dont s'entretiennent actuellement, à Winnipeg, nos ministres des finances.

Mais l'homme ne vit pas seulement de pain ... Aussi espérons-nous que le sous-comité du Centenaire du Manitoba chargé de subventionner les publications $\mathrm{du}$ centenaire facilitera aux officiers de la Société canadienne d'histoire de l'Église catholique la réalisation de leur rêve: par la publication intégrale de nos très riches conférences manitobaines, fournir aux esprits l'indispensable nourriture des gestes perpétuels de Dieu, dans cette Église dont nous sommes les heureux enfants.

A vous tous merci de votre charité, au cours de ce congrès, et au revoir, ici ou chez nous!

Adrien Pouliot, s.j.,

Historien et archiviste

de la Compagnie de Jésus à Québec. 